\title{
Niclosamide enhances the antitumor effects of radiation by inhibiting the hypoxia-inducible factor-1 $\alpha /$ vascular endothelial growth factor signaling pathway in human lung cancer cells
}

\author{
MEI XIANG ${ }^{*}$, ZIHONG CHEN* ${ }^{*}$, DONGHONG YANG* ${ }^{*}$ HAIWEN LI, YUFANG ZUO, JINGJING LI, \\ WENDIAN ZHANG, HECHAO ZHOU, DANXIAN JIANG, ZUMIN XU and ZHONGHUA YU
}

The Cancer Center, Affiliated Hospital of Guangdong Medical University, Zhanjiang, Guangdong 524000, P.R. China

Received October 27, 2015; Accepted January 4, 2017

DOI: $10.3892 / 01.2017 .6372$

\begin{abstract}
Lung cancer is one of the leading causes of cancer-associated mortality, worldwide. The overall survival rate remains low, but progress has been made in improving the diagnosis and treatment of lung cancer over the past decades. Niclosamide, a salicylanilide derivative used for the treatment of tapeworm infections, is safe, well tolerated, inexpensive and readily available. Previous studies have identified niclosamide as a potential anticancer agent. The present study demonstrated that niclosamide enhanced the effect of irradiation by inhibiting the hypoxia-inducible factor-1 $\alpha$ /vascular endothelial growth factor signaling pathway. These findings suggest that niclosamide may be a promising candidate for clinical evaluation as part of a combined regimen for the treatment of non-small cell lung cancer.
\end{abstract}

\section{Introduction}

Lung cancer is one of the leading causes of cancer-associated mortality worldwide, accounting for $>1000,000$ mortalities/year (1). Progress has been made in the diagnosis and treatment of lung cancer over the past decades (2). Concurrent chemoradiotherapy has been used to control locally advanced non-small cell lung cancer (NSCLC) (3). However, the improvements are modest, leading to only 4-5\% improvements in the five-year survival rates for cancer stages I-III (4). Therefore, the development of multimodal therapeutics with

Correspondence to: Dr Zhonghua Yu or Dr Zumin Xu, The Cancer Center, Affiliated Hospital of Guangdong Medical University, 57 South Renming Road, Zhanjiang, Guangdong 524000, P.R. China E-mail: zhonghua_yu@126.com

E-mail: zuminxu@163.com

${ }^{*}$ Contributed equally

Key words: niclosamide, lung cancer, radiosensivity, hypoxia-inducible factor-1 $\alpha$, vascular endothelial growth factor increased effectiveness is required in order to improve the rate of survival of patients with lung cancer.

Niclosamide, a salicylanilide derivative used for the treatment of tapeworm infections, is safe, well tolerated, inexpensive and readily available (5). A previous study identified niclosamide as a potential anticancer agent in in vitro and in vivo models (6). The inhibitory effects of niclosamide has been reported in a number of human tumor types, including breast cancer, prostate cancer, colon cancer, ovarian cancer, multiple myeloma, acute myelogenous leukemia, glioblastoma, head and neck cancer and lung cancer cells (7). In addition, niclosamide demonstrated synergistic effects when combined with chemotherapeutic agents, including oxaliplatin (8), Ara-C, etoposide and daunorubicin, and temozolomide (9). Furthermore, niclosamide may be able to reverse the resistance of human head and neck cancer and NSCLC cells to erlotinib $(10,11)$. The present study demonstrated that niclosamide enhanced the effects of irradiation by inhibiting the hypoxia inducible factor- $1 \alpha$ (HIF-1 $\alpha)$ /vascular growth factor (VEGF) signaling pathway. These results suggest that niclosamide may be a promising candidate for clinical evaluation as part of a combined regimen for the treatment of NSCLC.

\section{Materials and methods}

Cell culture and treatments. Human lung cancer cell lines, A549 and H1299 were purchased from the American Type Culture Collection (Manassas, VA, USA) and maintained by our laboratory (Zumin Xu, Affiliated Hospital of Guangdong Medical University) and cultured in RPMI-1640 (GE Healthcare; HyClone, Logan, UT, USA) supplemented with $10 \%$ fetal bovine serum (FBS; Biological Industries, Beit Haemek, Israel), $100 \mathrm{U} / \mathrm{ml}$ penicillin and $100 \mathrm{U} / \mathrm{ml}$ streptomycin in a humid atmosphere of $5 \% \mathrm{CO}_{2}$ at $37^{\circ} \mathrm{C}$.

Irradiation conditions. The human lung cancer cells were exposed to $4 \mathrm{MV} \mathrm{X}$-rays with various doses of radiation (0-8 Gy) at a dose rate of $0.6 \mathrm{~Gy} / \mathrm{min}$ at room temperature using a linear accelerator (Elekta AB, Stockholm, Sweden) and the source-skin-distance technique $(100 \mathrm{~cm})(12)$. The depth was set at $1 \mathrm{~cm}$ to the bottom of the 6 -well plate or 6 - $\mathrm{cm}$ dishes. 
Cell proliferation assay. Cells in the early log growth phase were trypsinized and plated in a 96-well plate at a density of $1 \times 10^{4}$ cells/well. Following $24 \mathrm{~h}$, the RPMI-1640 medium containing $10 \%$ FBS was removed and replaced with fresh RPMI-1640 medium supplemented with niclosamide at the indicated concentrations $(0,0.25,0.5,1,2,4,8,16$ and $32 \mu \mathrm{M})$ for 24 or $48 \mathrm{~h}$ at $37^{\circ} \mathrm{C}$ in the presence of $1 \%$ FBS. Cell density was evaluated using a Cell Counting kit-8 (CCK-8; Dojindo Molecular Technologies, Inc., Kumamoto, Japan) assay, according to the manufacturer's protocol. The absorbance of each well was determined at $450 \mathrm{~nm}$ using a microplate reader. The percentages of surviving cells from each group, relative to the control (untreated group), were defined as the proliferation rate. For these investigations, all experiments were repeated $\geq 3$ times.

Colony formation assay. Cells in the early log phase were trypsinized and plated in 6-well plates at 200, 400, 1,000, 2,000 and 4,000 cells/well, and cultured overnight at $37^{\circ} \mathrm{C}$ in order to allow for cell attachment. Subsequently, cells were treated with or without niclosamide $(0.8 \mu \mathrm{Mol} / 1)$ in $37^{\circ} \mathrm{C} \mathrm{CO}_{2}$ incubator for $24 \mathrm{~h}$, prior to irradiation with the exposure dose corresponding to $0,2,4,6$ or $8 \mathrm{~Gy}$. The cells were incubated in $37^{\circ} \mathrm{C} \mathrm{CO}_{2}$ incubator for 10 days to allow for the formation of colonies. Cells were fixed and stained with $0.5 \%$ crystal violet (Sigma-Aldrich; Merck Millipore, Darmstadt, Germany) at room temperature for $15 \mathrm{~min}$, and colonies containing $>50$ cells were counted under a light microscope. Survival curves were determined using the click multi-target model with GraphPad Prism 5.0 software (GraphPad Software Inc., La Jolla, CA, USA). Each point on the survival curve represents the mean surviving cell fraction of $\geq 3$ independent experiments.

Cell apoptosis analysis. The number of apoptotic cells was determined by flow cytometry using the Annexin V-fluorescein isothiocyanate (FITC) Apoptosis Detection kit (Kaiji Biotech Development Co., Ltd., Nanjing, China), as previously described (13). Cells in the early log phase were trypsinized at $37^{\circ} \mathrm{C}$ and plated in 6 -well plates at $2 \times 10^{5}$ cells per/well. Following $24 \mathrm{~h}$, the cells were treated with niclosamide $(0.8 \mu \mathrm{Mol} / \mathrm{l})$ alone or combined with $6 \mathrm{~Gy}$ radiation $(10 \mathrm{~min}$ exposure) at room temperature. Cells were then collected, washed three times with PBS, added to $1 \mathrm{ml}$ ethanol (70\%) and fixed for $2 \mathrm{~h}$ at $4^{\circ} \mathrm{C}$. Subsequently, the cells were washed with PBS 3 times and the supernatant was removed following centrifugation at $800 \mathrm{x}$ g for $10 \mathrm{~min}$ at room temperature. A total of $500 \mu \mathrm{l}$ Annexin V-binding buffer, $5 \mu \mathrm{l}$ Annexin V-FITC and $5 \mu \mathrm{l}$ propidium iodide (PI) was then added and incubated at room temperature in the dark for $15 \mathrm{~min}$. The rate of cell apoptosis was determined using flow cytometry (BD Biosciences, Franklin Lakes, NJ, USA) according to the manufacturer's protocol.

Western blot analysis. Following treatment with niclosamide and/or radiation (6 Gy), cells for immunoblotting were prepared as previously described (12). The PVDF membrane was then incubated with the appropriate primary antibody at $4^{\circ} \mathrm{C}$ overnight, including anti-HIF-1 $\alpha$ (cat. no. 14179S), anti-VEGF (cat. no. sc-152) (both 1:1,000; Cell Signaling Technology, Inc., Danvers, MA, USA) or anti- $\beta$-actin (cat. no. bsm-33139M, 1:1,500; Boster Biological Technology, Ltd., Wuhan, China). The protein of interest was detected following incubation with a goat anti-rabbit (cat. no. A0208, 1:1,500; Beyotime Institute of Biotechnology, Haimen, China) or anti-mouse (cat. no. A0216, 1:1,500; Beyotime Institute of Biotechnology, Haimen, China) IgG-horseradish peroxidase conjugated secondary antibody (dilution,) at $4^{\circ} \mathrm{C}$ for $2 \mathrm{~h}$. The band intensities were evaluated using ImageJ software version 1.41 (National Institutes of Health, Bethesda, MD, USA). Data are presented as the relative protein level normalized to $\beta$-actin, and the ratio of control samples was expressed as 1.0 .

Statistical analysis. All data are expressed as the mean \pm standard deviation. For comparisons between two groups, the Student's t-test method was used. One-way analysis of variance was used for comparison between $\geq 2$ groups. SPSS version 13.0 was used for all statistical analyses (SPSS, Inc., Chicago, IL, USA). $\mathrm{P}<0.05$ was considered to indicate a statistically significant difference.

\section{Results}

Niclosamide inhibits the proliferation of lung cancer cells in a dose-and time-dependent manner. The effects of niclosamide on the proliferation of H1299 and A549 cells were determined using a CCK- 8 assay. Increasing the treatment concentration of niclosamide and extending the treatment time from 24 to $48 \mathrm{~h}$ resulted in a significant reduction in viability of H1299 and A549 cells (Fig. 1). The 50\% inhibitory concentration $\left(\mathrm{IC}_{50}\right)$ of niclosamide on A549 cells was $3.368 \mu \mathrm{M}$ at $24 \mathrm{~h}$ and $0.99 \mu \mathrm{M}$ at $48 \mathrm{~h}$. The $\mathrm{IC}_{50}$ of niclosamide on H1299 cells was $1.383 \mu \mathrm{M}$ at $24 \mathrm{~h}$ and $0.836 \mu \mathrm{M}$ at $48 \mathrm{~h}$. To investigate the radiosensitization effect in human lung cancer cells, a niclosamide concentration of $0.8 \mu \mathrm{M}$ was used in subsequent experiments.

Niclosamide enhances the radiation response in human lung cancer cells. A colony formation assay was performed in order to evaluate whether niclosamide increased the radiosensitivity of lung cancer cells. Cells were pretreated with $0.8 \mu \mathrm{Mol} / 1$ niclosamide prior to radiation exposure at $0,2,4,6$ or $8 \mathrm{~Gy}$, and the surviving colonies were counted following a 10-day incubation. The radiation sensitivity was evaluated as the surviving fraction of cells at a clinically relevant dose of $2 \mathrm{~Gy}$, and sensitization enhancement ratios (SERs) were determined. The result of the clonogenic survival assay revealed that niclosamide enhanced the radiosensitivity of A549 and H1299 cells, and the SER was 2.323 and 1.684, respectively (Fig. 2). Therefore, the results indicate that niclosamide sensitized the cytotoxic effect of radiation treatment in lung cancer cells.

Niclosamide enhances radiation-induced apoptosis in lung cancer cells. In order to investigate whether niclosamide enhanced the radiation response of lung cancer cells by inducing apoptosis, A549 and H1299 cells were pretreated with $0.8 \mu \mathrm{Mol} / 1$ niclosamide for $24 \mathrm{~h}$, prior to the administration of 6 Gy radiation and a 36-h incubation. Subsequently, apoptotic cells were detected using PI and Annexin V flow 
A

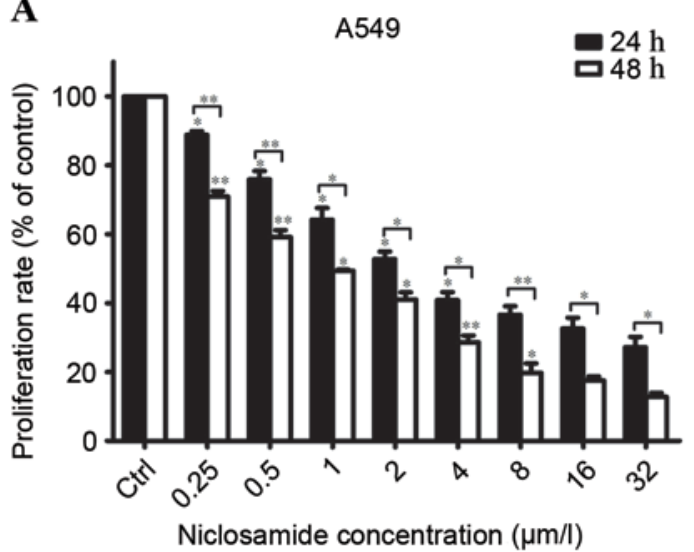

B

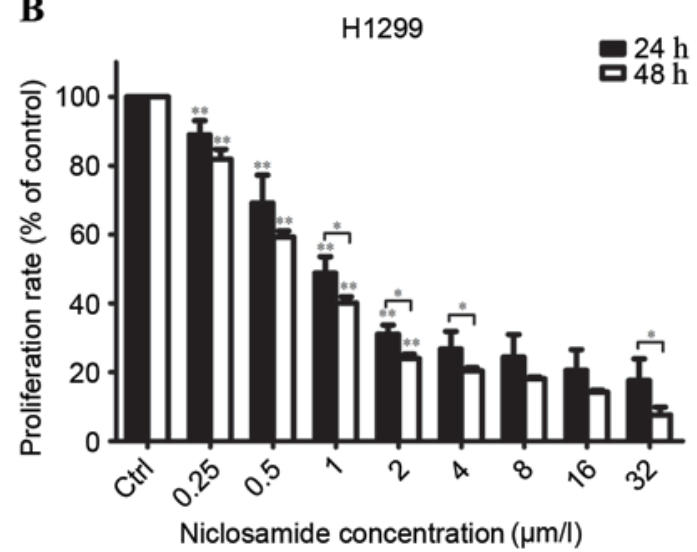

Figure 1. Niclosamide inhibits the proliferation of human lung cancer cells. Human lung cancer cell lines, (A) A549 and (B) H1299, were treated with niclosamide at various concentrations $(0,0.25,0.5,1,2,4,8,16$ and $32 \mu \mathrm{M})$ for 24 or $48 \mathrm{~h}$, and the proliferation rates were then determined using a Cell Counting kit-8. Niclosamide significantly inhibited the viability of A549 and H1299 cell lines in a dose- and time-dependent manner. All data are presented as the mean \pm SD from three independent experiments. Cell proliferation in untreated control cells was assigned as $100 \%$. ${ }^{*}<0.05 ;{ }^{* *} \mathrm{P}<0.01 \mathrm{vs}$. the control cells; the bars represent SD. SD, standard deviation.
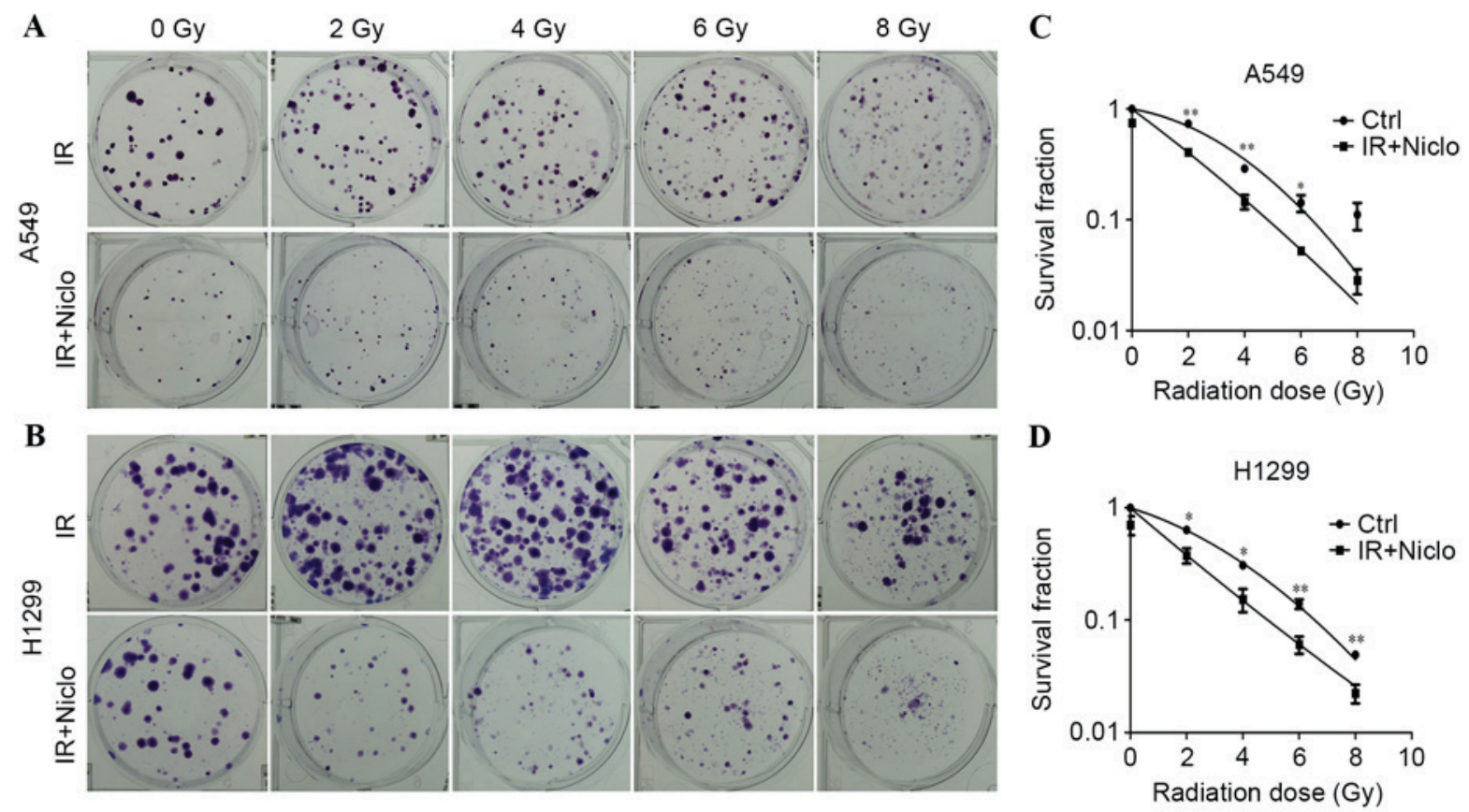

Figure 2. The effect of niclosamide pretreatment followed by irradiation on the survival fraction of human lung cancer cells. Cells were treated with niclosamide $(0.8 \mu \mathrm{m})$, radiation or pretreated with niclosmide $(0.8 \mu \mathrm{M})$ for $24 \mathrm{~h}$ followed by $0-8$ Gy radiation and allowed to grow for 14 days. Representative images of colony formation of A549 (A) and H1299 (B) cells are presented. Survival fractions of A549 (C) and H1299 cells (D) were obtained from the results of the colony forming assays. Survival curves were fitted using the click multi-target model. Niclosamide remarkably enhanced the radiosensitivity of human lung cancer cells with SERs of 2.323 for A549, and 1.684 for H1299 cells. All data are presented as the mean \pm standard deviation from three independent experiments. ${ }^{*} \mathrm{P}<0.05$, IR vs. IR+Niclo group; ${ }^{* *} \mathrm{P}<0.01$, IR vs. IR+Niclo group. IR, irradiation; Niclo, niclosamide; Ctrl, control; SER, sensitization enhancement ratio.

cytometry. The results reveal that treatment with niclosamide and radiation significantly increased cell apoptosis compared with cells exposed to radiation alone (A549, P<0.0001; H1299, $\mathrm{P}<0.0001)$. The apoptotic rate of the control, niclosamide, radiation and niclosamide combined with radiation treatment in A549 cells were $6.5 \pm 1.0,61.5 \pm 14.1,19.8 \pm 1.9$ and $91.3 \pm 1.52 \%$, respectively. The apoptotic rate of the control, niclosamide, radiation and niclosamide combined with radiation treatment in H1299 cells were 4.1 $\pm 1.8,61.2 \pm 1.45,14.2 \pm 2.1$ and $93.8 \pm 1.53 \%$, respectively (Fig. 3).
Niclosamide inhibits radiation-induced $\mathrm{HIF}-1 \alpha / V E G F$ expression in lung cancer cells. Western blot analysis was performed in order to detect the effects of radiation and/or niclosamide $(0.8 \mu \mathrm{Mol} / 1)$ treatment on the expression levels of HIF-1 $\alpha$ and VEGF. The HIF-1 $\alpha$ and VEGF proteins were detected, and niclosamide alone was able to decrease the expression of HIF-1 $\alpha$ and VEGF proteins. However, the expression of HIF-1 $\alpha$ and VEGF proteins was remarkably increased following irradiation, and niclosamide combined with irradiation significantly downregulated the radiation-induced HIF-1 $\alpha$ 
A
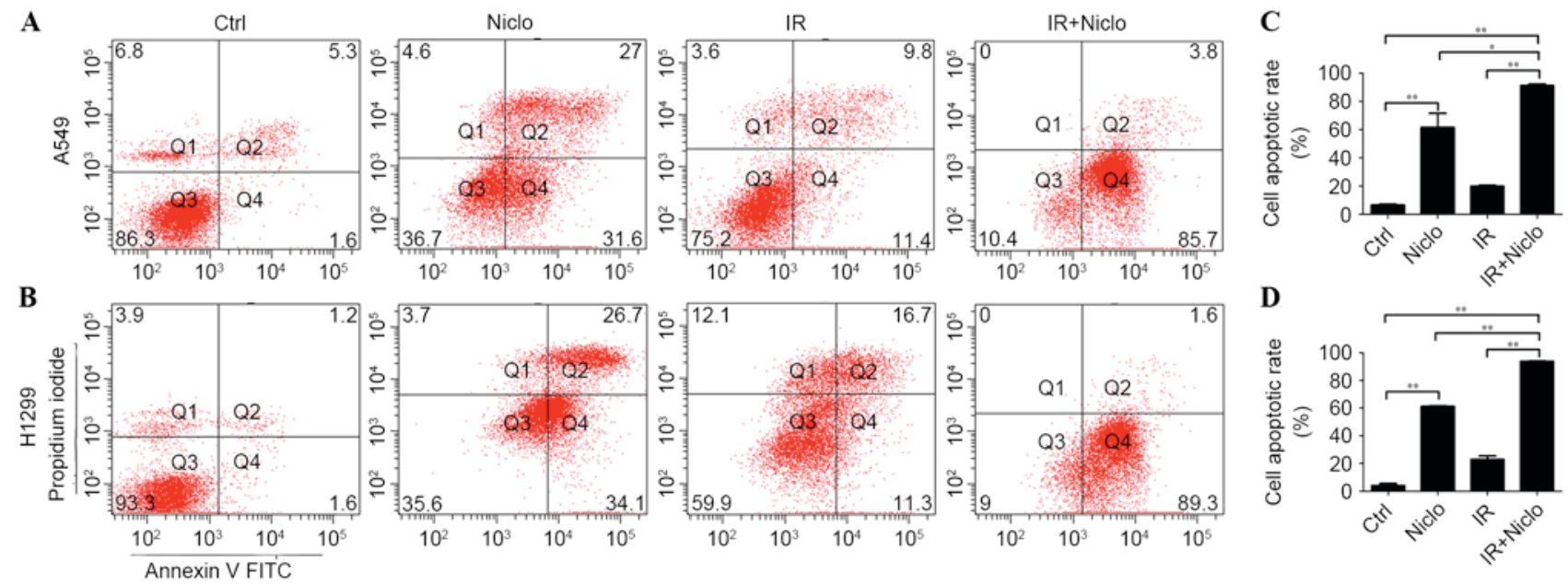

Figure 3. Effect of niclosamide combined with irradiation on the apoptosis of lung cancer cells. Cells were treated with niclosamide (0.8 $\mu$ m), radiation or pretreated with niclosamide $(0.8 \mu \mathrm{m})$ for $24 \mathrm{~h}$, followed by 6 Gy radiation. Cells were harvested and stained with Annexin V-PI and cell apoptosis was detected by flow cytometry. The apoptotic rate of combined treatments was significantly higher compared with the niclosamide or irradiation treatment groups. Representative images of flow cytometric analysis of the various treatments of (A) A549 and (B) H1299 cells. (C) Apoptotic rate of A549 cells treated with control, IR, Niclo and Niclo combined with IR were $6.5 \pm 1.0,61.5 \pm 14.1,19.8 \pm 1.9$ and $91.3 \pm 1.52 \%$, respectively. (D) Apoptotic rate of H1299 cells treated with control, IR, Niclo and Niclo combined with IR were 4.1 $\pm 1.8,61.2 \pm 1.45,14.2 \pm 2.1$ and $93.8 \pm 1.53 \%$, respectively. Data are presented as the mean \pm standard deviation from three independent experiments. ${ }^{*} \mathrm{P}<0.05 ;{ }^{* *} \mathrm{P}<0.01$. Ctrl, control; Niclo, niclosamide; IR, irradiation; FITC, fluorescein isothiocyanate; PI, propidium iodide.

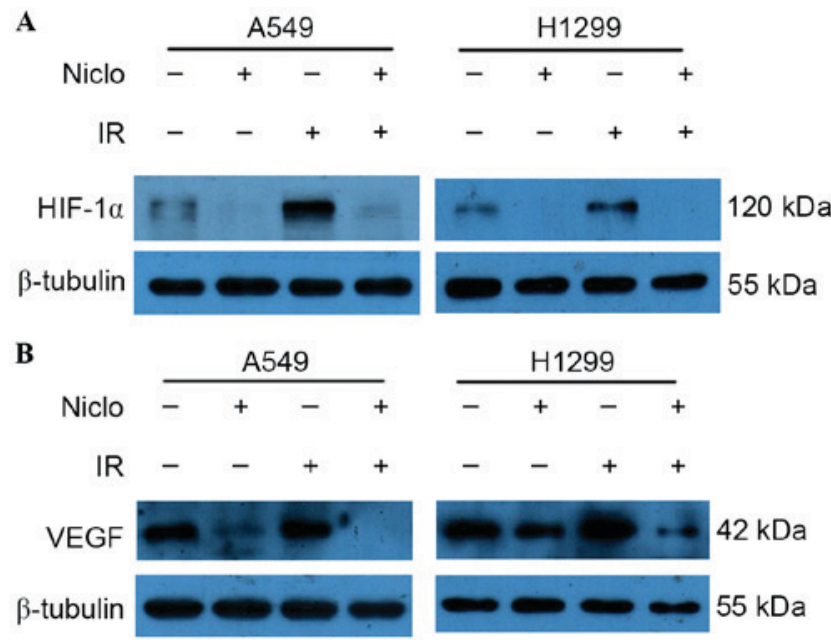

Figure 4. Effects of niclosamide combined with irradiation on the expression levels of HIF-1 $\alpha$ and VEGF in lung cancer cells. A549 and H1299 cells were treated with niclosamide $(0.8 \mu \mathrm{M})$ alone or combined with 6 Gy radiation. Whole cell lysates were prepared and western blot analysis was performed using (A) anti-HIF-1 $\alpha$ or (B) anti-VEGF antibodies. The HIF-1 $\alpha$ and VEGF protein expression levels were elevated by radiation, and niclosamide treatment significantly down-regulated the irradiation-mediated HIF-10 and VEGF up-regulation in both A549 and H1299 cells. HIF-1 $\alpha$, hypoxia inducible factor-1 $\alpha$; VEGF, vascular growth factor; Niclo, niclosamide; IR, irradiation.

(Fig. 4A) and VEGF (Fig. 4B) upregulation observed in A549 and H1299 cells. These results suggest that niclosamide may induce radiosensitizing effects via the downregulation of the HIF-1 $\alpha$ /VEGF signaling pathway.

\section{Discussion}

In the present study, it was observed that niclosamide inhibited the proliferation of lung cancer cells in a dose- and time-dependent manner. Niclosamide pretreatment followed by irradiation may be able to enhance the radiosensitivity of lung cancer cell lines by suppressing the HIF-1 $\alpha /$ VEGF signaling pathway.

Previous studies have identified niclosamide as a potential antitumor agent, and further investigations suggested that niclosamide may target a number of signaling pathways, including nuclear factor- $\kappa \mathrm{B}$, reactive oxygen species (9), Wnt/ $\beta$-catenin (8), Notch (14), mammalian target of rapamycin complex 1 (15) and signal transducer and activator of transcription 3 (STAT3) (16). Furthermore, previous studies have investigated the effect of niclosamide on the response of human lung cancer cells to radiation. You et al (17) demonstrated that ionizing radiation induced the phosphorylation of Janus-associated kinase-2 and STAT3 in numerous types of human lung cancer cells, whereas niclosamide reduced STAT3 nuclear localization in radioresistant lung cancer cells. In addition, it was revealed that inhibition of STAT3 by niclosamide may overcome radioresistance in lung cancer, suggesting that niclosamide could potentially improve the outcome of lung cancer, particularly for patients with resistance to radiotherapy. Lee et al (18) demonstrated that niclosamide enhanced cell death following the radiation exposure of H1299 cells by activation of the p38 mitogen-activated protein kinase/c-Jun signaling axis. The present study also observed the radiosensitizing effects of niclosamide on H1299 and A549 NSCLC cell lines. The SERs of H1299 and A549 were 1.684 and 2.323, respectively (Fig. 2). These results suggest that niclosamide may be a potential radiation sensitizer for lung cancer.

Hypoxia commonly occurs in solid tumors (19). Hypoxia activates a number of signaling pathways including HIFs, which may lead to radiation resistance in a number of cancer subtypes (20). HIFs are heterodimeric basic helix-loop-helix Per-Arnt-Sim family transcription factors composed of $\alpha$ and $\beta$ subunits (21). When dimerized, HIFs bind to hypoxia 
responsive elements in the promoter or enhancer regions of target genes. The HIF-1 $\alpha$ is regulated by oxygen tension. Under normal oxygen levels, HIF-1 $\alpha$ subunits are less abundant at the protein level due to prolyl hydroxylase mediated degradation, which decreases the half life of HIF-1 $\alpha$ to 5-10 min despite continued transcription of HIF-1 $\alpha$ mRNA. Under hypoxia, HIF-1 $\alpha$ is stable and no longer degraded; therefore, HIF proteins are able to rapidly alter signaling pathways involved in cellular metabolism, angiogenesis and survival (22). HIF-1 $\alpha$ serves an important role in the response to hypoxia and transcriptional activation of genes including $V E G F$, in order to promote the resistance of cancer cells to radiotherapy (23). However, whether niclosamide enhances the radiosensitivity of lung cancer by suppressing the HIF-1 $\alpha /$ VEGF signaling pathway requires further investigation. Therefore, the present study detected the impact of niclosamide and/or radiation treatment on the expression levels of HIF-1 $\alpha$ and VEGF in lung cancer cells. The results demonstrated that irradiation may induce the expression of HIF- $1 \alpha$ and VEGF in A549 and H1299 cells. However, niclosamide downregulated the irradiation-induced expression of HIF-1 $\alpha$ (Fig. 4A) and VEGF (Fig. 4B). The present study suggested that niclosamide may enhance the radiosensitivity of human lung cancer cells by suppressing the HIF-1 $\alpha$ /VEGF signaling pathway.

Niclosamide was previously identified as a potent STAT3 inhibitor (16). STAT3 acts as a signal transducer and transcription factor (24). STAT3 protein has been revealed to bind to the HIF-1 $\alpha$ promoter in vitro and in vivo under hypoxia (25). In addition, STAT3 was considered to be a novel regulator of HIF- $1 \alpha$ activity by participating in the transcriptional unit with HIF- $1 \alpha$ and p300, which leads to hypoxia-mediated transcriptional activation of HIF-1 target genes, including VEGF (26). Furthermore, the inhibition of STAT3 displayed an antitumor effect and promoted chemosensitivity and radiosensitivity in nasopharyngeal carcinoma and head and neck squamous cell carcinoma by modulating HIF-1 $\alpha$ expression $(27,28)$. Therefore, niclosamide may inhibit HIF-1 $\alpha /$ VEGF expression via the STAT3 signaling pathway.

In conclusion, the present study demonstrated that niclosamide exhibited a strong radiosensitizing potential in lung cancer cells by reducing the expression of HIF-1 $\alpha$ and VEGF. These findings suggest that niclosamide may be a novel potent radiosensitizer and a promising candidate for clinical evaluation as part of a combined regimen for the treatment of NSCLC.

\section{Acknowledgements}

The present study was supported by the National Nature Science Foundation of China (grant no. 81201736) and the Natural Science Foundation of Guangdong Province (grant no. 2015A030310460).

\section{References}

1. Siegel R, Naishadham D and Jemal A: Cancer statistics, 2012. CA Cancer J Clin 62: 10-29, 2012

2. Minguet J, Smith KH and Bramlage P: Targeted therapies for treatment of non-small cell lung cancer-Recent advances and future perspectives. Int J Cancer 138: 2549-2561, 2016.
3. O'Rourke N, Roqué I Figuls M, Farré Bernadó N and Macbeth F: Concurrent chemoradiotherapy in non-small cell lung cancer. Cochrane Database Syst Rev: CD002140, 2010.

4. Johnson DH, Schiller JH and Bunn PA Jr: Recent clinical advances in lung cancer management. J Clin Oncol 32: 973-982, 2014.

5. Merschjohann $\mathrm{K}$ and Steverding D: In vitro trypanocidal activity of the anti-helminthic drug niclosamide. Exp Parasitol 118: 637-640, 2008.

6. Li Y,Li PK, Roberts MJ, Arend RC, Samant RS and Buchsbaum DJ: Multi-targeted therapy of cancer by niclosamide: A new application for an old drug. Cancer Lett 349: 8-14, 2014.

7. Pan JX, Ding K and Wang CY: Niclosamide, an old antihelminthic agent, demonstrates antitumor activity by blocking multiple signaling pathways of cancer stem cells. Chin J Cancer 31: 178-184, 2012.

8. Osada T, Chen M, Yang XY, Spasojevic I, Vandeusen JB, Hsu D, Clary BM, Clay TM, Chen W, Morse MA and Lyerly HK: Antihelminth compound niclosamide downregulates Wnt signaling and elicits antitumor responses in tumors with activating APC mutations. Cancer Res 71: 4172-4182, 2011.

9. Jin Y, Lu Z, Ding K, Li J, Du X, Chen C, Sun X, Wu Y, Zhou J and Pan J: Antineoplastic mechanisms of niclosamide in acute myelogenous leukemia stem cells: Inactivation of the NF-kappaB pathway and generation of reactive oxygen species. Cancer Res 70: 2516-2527, 2010.

10. Li R, Hu Z, Sun SY, Chen ZG, Owonikoko TK, Sica GL, Ramalingam SS, Curran WJ, Khuri FR and Deng X: Niclosamide overcomes acquired resistance to erlotinib through suppression of STAT3 in non-small cell lung cancer. Mol Cancer Ther 12: 2200-2212, 2013.

11. Li R, You S, Hu Z, Chen ZG, Sica GL, Khuri FR, Curran WJ, Shin DM and Deng X: Inhibition of STAT3 by niclosamide synergizes with erlotinib against head and neck cancer. PLoS One 8: e74670, 2013

12. Li H, Chen X, Yu Y, Wang Z, Zuo Y, Li S, Yang D, Hu S, Xiang M, Xu Z and Yu Z: Metformin inhibits the growth of nasopharyngeal carcinoma cells and sensitizes the cells to radiation via inhibition of the DNA damage repair pathway. Oncol Rep 32: 2596-2604, 2014

13. Xu Z, Zuo Y, Wang J, Yu Z, Peng F, Chen Y, Dong Y, Hu X, Zhou Q, Ma H, et al: Overexpression of the regulator of G-protein signaling 5 reduces the survival rate and enhances the radiation response of human lung cancer cells. Oncol Rep 33: 2899-2907, 2015.

14. Wang AM, Ku HH, Liang YC, Chen YC, Hwu YM and Yeh TS: The autonomous notch signal pathway is activated by baicalin and baicalein but is suppressed by niclosamide in K562 cells. J Cell Biochem 106: 682-692, 2009.

15. Fonseca BD, Diering GH,Bidinosti MA,DalalK, Alain T,Balgi AD, Forestieri R, Nodwell M, Rajadurai CV, Gunaratnam C, et al: Structure-activity analysis of niclosamide reveals potential role for cytoplasmic $\mathrm{pH}$ in control of mammalian target of rapamycin complex 1 (mTORC1) signaling. J Biol Chem 287: 17530-17545, 2012.

16. Ren X, Duan L, He Q, Zhang Z, Zhou Y, Wu D, Pan J, Pei D and Ding K: Identification of niclosamide as a new small-molecule inhibitor of the STAT3 signaling pathway. ACS Med Chem Lett 1: 454-459, 2010.

17. You S, Li R, Park D, Xie M, Sica GL, Cao Y, Xiao ZQ and Deng X: Disruption of STAT3 by niclosamide reverses radioresistance of human lung cancer. Mol Cancer Ther 13: 606-616, 2014.

18. Lee SL, Son AR, Ahn J and Song JY: Niclosamide enhances ROS-mediated cell death through c-Jun activation. Biomed Pharmacother 68: 619-624, 2014.

19. Rademakers SE, Span PN, Kaanders JH, Sweep FC, van der Kogel AJ and Bussink J: Molecular aspects of tumour hypoxia. Mol Oncol 2: 41-53, 2008.

20. Meijer TW, Kaanders JH, Span PN and Bussink J: Targeting hypoxia, HIF-1, and tumor glucose metabolism to improve radiotherapy efficacy. Clin Cancer Res 18: 5585-5594, 2012.

21. Gu YZ, Hogenesch JB and Bradfield CA: The PAS superfamily: Sensors of environmental and developmental signals. Annu Rev Pharmacol Toxicol 40: 519-561, 2000.

22. Jaakkola P, Mole DR, Tian YM, Wilson MI, Gielbert J, Gaskell SJ, von Kriegsheim A, Hebestreit HF, Mukherji M, Schofield CJ, et al: Targeting of HIF-alpha to the von Hippel-Lindau ubiquitylation complex by O2-regulated prolyl hydroxylation. Science 292: 468-472, 2001 
23. Ghattass K, Assah R,El-Sabban M and Gali-Muhtasib H: Targeting hypoxia for sensitization of tumors to radio- and chemotherapy. Curr Cancer Drug Targets 13: 670-685, 2013.

24. Li B and Huang C: Regulation of EMT by STAT3 in gastrointestinal cancer (Review). Int J Oncol 50: 753-767, 2017.

25. Niu G, Briggs J, Deng J, Ma Y, Lee H, Kortylewski M, Kujawski M, Kay H, Cress WD, Jove R and Yu H: Signal transducer and activator of transcription 3 is required for hypoxia-inducible factor-1alpha RNA expression in both tumor cells and tumor-associated myeloid cells. Mol Cancer Res 6: 1099-1105, 2008.
26. Jung JE, Lee HG, Cho IH, Chung DH, Yoon SH, Yang YM, Lee JW, Choi S, Park JW, Ye SK and Chung MH: STAT3 is a potential modulator of HIF-1-mediated VEGF expression in human renal carcinoma cells. FASEB J 19: 1296-1298, 2005.

27. Pan Y, Zhou F, Zhang R and Claret FX: Stat 3 inhibitor Stattic exhibits potent antitumor activity and induces chemo- and radio-sensitivity in nasopharyngeal carcinoma. PLoS One 8: e54565, 2013.

28. Adachi M, Cui C, Dodge CT, Bhayani MK and Lai SY: Targeting STAT3 inhibits growth and enhances radiosensitivity in head and neck squamous cell carcinoma. Oral Oncol 48: 1220-1226, 2012. 